\title{
CARACTERÍSTICAS DA ESPIGA DO MILHO DOCE PRODUZIDO SOB DIFERENTES LÂMINAS DE IRRIGAÇÃO E DOSES NITROGENADAS ${ }^{1}$
}

\author{
Epitácio José de Souza ${ }^{2}$, Fernando França da Cunha ${ }^{3}$, Fernando Fagner Magalhães ${ }^{4}$, Thiago Ramos da Silva ${ }^{5}$, \\ Osvaldir Feliciano dos Santos ${ }^{6}$
}

\begin{abstract}
RESUMO
Objetivou-se, neste trabalho, avaliar as características da espiga do milho doce produzido sob diferentes doses de adubação nitrogenada e lâminas de irrigação, em duas épocas de cultivo na região nordeste do Mato Grosso do Sul. O experimento foi conduzido em parcelas subsubdivididas, tendo nas parcelas quatro lâminas de irrigação $(50,75,100$ e $125 \%$ da evapotranspiração da cultura - ETc), nas subparcelas quatro doses de nitrogênio em cobertura (0, 100, 200 e $300 \mathrm{~kg} \mathrm{ha}^{-1}$ ) e nas sub-subparcelas duas épocas de cultivo (Inverno/Primavera e Verão/Outono), no delineamento em blocos casualizados, com quatro repetições. Foram avaliadas as características: número de palha por espiga, comprimento de espiga, diâmetro de espiga, número de grãos por fileira, número de fileiras por espiga, diâmetro de sabugo, comprimento de grão, número de grãos por espiga e peso de espiga. O milho doce apresentou maior qualidade de espiga na época Verão/Outono e não foi afetado pela adubação nitrogenada. Na época Inverno/Primavera, o milho doce deve ser irrigado com reposição de $85 \%$ da ETc, enquanto que no Verão/Outono, com 50\% da ETc.
\end{abstract}

Palavras-chave: adubação, irrigação por gotejamento, sazonalidade, Zea mays var. Saccharata Sturt

\section{ABSTRACT \\ EAR CHARACTERISTICS OF SWEET CORN PRODUCED UNDER DIFFERENT IRRIGATION DEPTHS AND NITROGEN LEVELS}

This study aimed to evaluate the sweet corn cob characteristics under different levels of nitrogen fertilization and irrigation depths in two cropping seasons in northeastern region of Mato Grosso do Sul, Brazil. The experiment was conducted in of split plot scheme, having in the plots four irrigation depths $(50,75,100$ and $125 \%$ of crop evapotranspiration-ETc) and in the subplots, four nitrogen rates $\left(0,100,200\right.$ and $\left.300 \mathrm{~kg} \mathrm{ha}^{-1}\right)$ and in the sub-subplots, two cropping seasons (Winter/Spring and Summer/Autumn), in the randomized blocks design with four replication. The following characteristics were evaluated: straw number, ear length, ear diameter, kernels number per row, rows number, cob diameter, grain length, grains number and ear weight. Sweet corn showed higher ear quality at the Summer/Autumn season and was not affected by nitrogen fertilization. At the time Winter/Spring season, sweet corn should be irrigated with replacement of $85 \%$ of ETc, while in Summer/Autumn season with 50\% ETc.

Keywords: crop period, drip irrigation, fertilization, Zea mays var. Saccharata Sturt

\section{Recebido para publicação em 07/05/2015. Aprovado em 07/03/2016.}

1 - Extraído da dissertação de Mestrado do Primeiro Autor.

2 - Engenheiro Agrônomo, Doutorando em Agronomia, UNESP/Ilha Solteira, SP. E-mail: epitacio_jose@hotmail.com

3 - Doutor em Engenharia Agrícola, Professor Adjunto, UFV/Viçosa, MG. E-mail: fernando.cunha@ufv.br

4 - Graduando em Agronomia, UFMS/Chapadão do Sul, MS. E-mail: magalhaes.fernandof@gmail.com

5 - Graduando em Agronomia, UFMS/Chapadão do Sul, MS. E-mail: thiago.ramossilva10@gmail.com

6 - Engenheiro Agrônomo, Mestrando em Agronomia, UFMS/Chapadão do Sul, MS. E-mail: osvaldir.feliciano@gmail.com

50 REVENG
$50-62 \mathrm{p}$.

ENGENHARIA NA AGRICULTURA, VIÇOSA - MG, V.24 N.1, JANEIRO / FEVEREIRO 2016 


\section{INTRODUÇÃO}

O milho doce (Zea mays L. var. saccharata Sturt) é uma hortaliça destinada ao consumo humano, de cultivo intensivo e alto valor agregado. Pode ser comercializado após o processamento industrial na forma de conserva ou enlatado, desidratado ou consumido in natura, congelado na forma de espigas ou grãos, como baby corn ou minimilho se colhido antes da polinização (LUZ et al., 2014). A principal diferença entre o milho comum e o milho doce é a composição de seu endosperma, devido aos seus altos teores de açúcares em relação ao amido (KWIATKOWSKI; CLEMENTE, 2007).

De acordo com Pereira Filho e Cruz (2002), é desejável que as espigas do milho doce apresentem características como bem granadas, grandes, cilíndricas, sabugos claros e finos, grãos dentados, amarelos, saborosos, adocicados e macios, para obter uma boa aceitação no mercado tanto para o consumo in natura ou para a indústria de conserva.

Além de tais características, outros autores salientam ainda que as espigas devem apresentar grãos com o comprimento em torno de 11 a 12 mm (LUCHSINGER; CAMILO, 2008), número de palhas inferior a 14, pois acima disso pode comprometer o rendimento industrial (OKUMURA et al., 2013), porém não inferior a 7 , pois pode favorecer o ataque de pragas (SAWAZAKI et al., 1990).

Para obtenção de espigas com estas características exigidas pelo mercado, é necessário o uso adequado da água por meio da irrigação e o manejo da adubação nitrogenada. A instabilidade do regime pluvial torna-se um dos fatores que restringe o desenvolvimento da agricultura, pois mesmo dentro de estações chuvosas, observam-se momentos de déficit hídrico. Segundo Kwiatkowski e Clemente (2007) a reposição de água via irrigação permite ao produtor escalonar sua produção, assim atendendo a demanda comercial.

O manejo adequado de um sistema de irrigação deverá ser capaz de propiciar ao agricultor o uso eficiente da água para aumentar a produtividade das culturas, reduzir os custos de produção e, consequentemente, maximizar o retorno dos investimentos. Porém, as lâminas ótimas de irrigação podem variar em função das condições edafoclimáticas da região. Diversos autores têm estudado lâminas de irrigação para cultura do milho doce e encontraram diferentes consumos ótimos: Heinemann et al. (2001) em Sete Lagoas, MG (385 mm no Verão), Garcia et al. (2009) em Williamson no Estados Unidos da América (343 $\mathrm{mm}$ no Inverno e $260 \mathrm{~mm}$ na Primavera) e Brito et al. (2013) em Pombal, PB (767,5 mm no Verão).

Os benefícios da reposição hídrica no solo são maximizados quando associados a outros manejos, como a nutrição mineral das culturas agrícolas. Do ponto de vista nutricional, o milho doce é mais exigente em fertilidade do solo, em relação ao milho comum (OKUMURA et al., 2013). Esta exigência é justificada pelo metabolismo mais intenso para sintetizar açúcares, em um ciclo mais curto (CARMO et al., 2012).

No manejo da adubação, o nitrogênio merece destaque especial, pois conforme verificado por Okumura et al. (2011), esse macronutriente é absorvido em maior quantidade pelo milho doce, afetando seu rendimento. Segundo Borin et al. (2010), com o uso da irrigação, os riscos de quebra na produção são minimizados e esse fato contribui para que os produtores utilizem fertilizantes em maiores quantidades, na expectativa de aumento de produtividade. Farinelli e Lemos (2010) afirmam que o aumento das doses de adubo nitrogenado acaba reduzindo a eficiência do seu uso, em consequência disso, os danos econômicos e ambientais são aumentados. A redução destes danos pode ser obtida com a identificação de doses que visem maximizar o efeito da adubação.

Objetivou-se avaliar o efeito da irrigação e da adubação nitrogenada nas características de espiga do milho doce em duas épocas de cultivo na região nordeste do Mato Grosso do Sul.

\section{MATERIAL E MÉTODOS}

$\mathrm{O}$ experimento foi conduzido na área experimental da Universidade Federal de Mato Grosso do Sul, campus de Chapadão do SulMS, localizado nas coordenadas $18^{\circ} 46^{\prime} 24.38^{\prime \prime}$, $52^{\circ} 37 ' 23.75^{\prime \prime O}$ e altitude de $820 \mathrm{~m}$. O clima, segundo classificação de Koppen, é do tipo tropical úmido (Aw), com estações bem definidas, chuvosa no verão e seca no inverno (CASTRO et al., 2012). 
O solo é classificado como Latossolo Vermelho Amarelo Distrófico, textura argilosa, com massa específica de $1,21 \mathrm{~g} \mathrm{~cm}^{-3}$ e teores de água equivalente à capacidade de campo e ponto de murcha permanente da planta de 0,2632 e 0,1887 $\mathrm{dm}^{3} \mathrm{dm}^{-3}$, respectivamente.

Os atributos químicos do solo foram determinados antes de cada cultivo e realizados no Laboratório Inside de Chapadão do Sul-MS (Quadro 1).

O experimento foi conduzido em parcelas sub-subdivididas, tendo nas parcelas lâminas de irrigação, nas subparcelas doses de nitrogênio e nas sub-subparcelas as épocas de cultivo, no delineamento em blocos casualizados, com quatro repetições.

As lâminas de irrigação foram para reposição de $50,75,100$ e $125 \%$ da evapotranspiração da cultura (ETc). As doses de nitrogênio em cobertura foram de $0,100,200$ e $300 \mathrm{~kg} \mathrm{ha}^{-1}$. As épocas de cultivo do milho doce abrangeram as épocas Inverno/Primavera (17/8/2012 a 24/11/2012) e Verão/Outono (2/3/2013 a 31/05/2013).

As unidades experimentais foram constituídas de parcelas com 2,5 $\mathrm{m}$ de comprimento (bordadura de $0,5 \mathrm{~m}$ ) e 4,8 $\mathrm{m}$ de largura (bordadura de $0,8 \mathrm{~m}$ ), resultando em uma área total de $12 \mathrm{~m}^{2} \mathrm{e}$ útil de 4,8 $\mathrm{m}^{2}$.

O preparo do solo para a instalação dos experimentos constituiu-se de uma aração e uma gradagem. A correção da acidez do solo foi realizada utilizando calcário dolomítico com PRNT de $85 \%$, conforme recomendações de Sousa e Lobato (2004). O calcário foi aplicado após a operação de aração, em seguida foi realizada a gradagem para a sua incorporação.

A adubação de plantio foi realizada de acordo com recomendações de Sousa e Lobato (2004) e, em função dos atributos químicos do solo (Quadro 1). Foram utilizadas em ambas as épocas de cultivo, para fornecimento de nitrogênio, fósforo e potássio, as fontes uréia, superfosfato simples e cloreto de potássio, respectivamente.

As semeaduras foram realizadas nos dias 17/8/2012 (Inverno/Primavera) e 2/3/2013 (Verão/ Outono), com o espaçamento de $0,8 \mathrm{~m}$ entre fileiras, adotando uma densidade de 75.000 sementes $\mathrm{ha}^{-1}$. Foi utilizado o híbrido simples Tropical $P_{l u s^{\circledR}}$, da empresa Syngenta, que apresenta como características: alto potencial produtivo, ciclo de 90 a 110 dias, coloração de grão amarelo-claro, pericarpo fino e sabor adocicado e resistência às principais doenças.

As sementes vieram tratadas da indústria de beneficiamento com Fludioxinil e Metalaxyl-M (3,75 g i.a./100 kg sementes), Carboxin e Thiram (188 g i.a./100 kg sementes), e Captan (120 g i.a./100 $\mathrm{kg}$ sementes). Antes da semeadura, as

Quadro 1. Resultados da análise química do solo da área experimental em diferentes épocas de cultivo. (Inverno/Primavera - Inv/Pri e Verão/Outono - Ver/Out). Chapadão do Sul - MS, UFMS-CPCS, 2012-2013.

\begin{tabular}{|c|c|c|c|c|c|c|c|c|c|c|c|c|}
\hline \multirow{2}{*}{ Época } & \multirow{2}{*}{$\begin{array}{c}\text { Camada } \\
(\mathrm{cm})\end{array}$} & \multirow{2}{*}{\multicolumn{2}{|c|}{$\begin{array}{c}\mathrm{pH} \\
\mathrm{CaCl}_{2}\end{array}$}} & $\mathrm{Ca}+\mathrm{Mg}$ & $\mathrm{Ca}$ & & $\mathrm{Mg}$ & $\mathrm{Al}$ & $\mathrm{H}+\mathrm{Al}$ & $\mathrm{K}$ & $\mathrm{K}$ & $\mathrm{P}(\mathrm{mel})$ \\
\hline & & & & \multicolumn{7}{|c|}{----- $\mathrm{cmol}_{\mathrm{c}} \mathrm{dm}^{-3}$---- } & \multicolumn{2}{|c|}{--- $\mathrm{mg} \mathrm{dm}^{-3}$--- } \\
\hline \multirow{2}{*}{ Inv/Pri } & $0-20$ & \multicolumn{2}{|c|}{5,3} & 4,20 & 3,30 & & , 90 & 0,08 & 4,9 & 0,29 & 113 & 13,8 \\
\hline & $20-40$ & \multicolumn{2}{|c|}{5,1} & 2,40 & 1,90 & &, 50 & 0,24 & 5,0 & 0,12 & 47 & 4,8 \\
\hline \multirow{2}{*}{ Ver/Out } & $0-20$ & \multicolumn{2}{|c|}{4,8} & 4,40 & 3,40 & & 1,00 & 0,09 & 4,8 & 0,13 & 52 & 4,8 \\
\hline & $20-40$ & \multicolumn{2}{|c|}{4,6} & 2,90 & 0,60 & &, 60 & 0,15 & 5,1 & 0,10 & 38 & 2,6 \\
\hline \multirow{2}{*}{ Época } & Camada & $\mathrm{S}$ & $\mathrm{B}$ & $\mathrm{Cu}$ & $\mathrm{Fe}$ & $\mathrm{Mn}$ & Z & & $\mathrm{MO}$ & \multirow{2}{*}{\multicolumn{2}{|c|}{$\frac{\text { CTC }}{\mathrm{cmol} \mathrm{dm}^{-3}}$}} & SB \\
\hline & $(\mathrm{cm})$ & \multicolumn{7}{|c|}{------------- mg dm³ } & $\mathrm{g} \mathrm{dm}^{-3}$ & & & $\%$ \\
\hline \multirow{2}{*}{ Inv/Pri } & $0-20$ & 24,4 & 0,29 & 0,4 & 46 & 12,0 & 4 & & 40,2 & \multicolumn{2}{|c|}{9,4} & 47,8 \\
\hline & $20-40$ & 24,6 & 0,22 & 0,4 & 40 & 5,9 & 2 & & 27,0 & \multicolumn{2}{|c|}{7,5} & 33,5 \\
\hline \multirow{2}{*}{ Ver/Out } & $0-20$ & 4,6 & 0,16 & 0,5 & 43 & 9,2 & 3 & & 35,8 & \multicolumn{2}{|c|}{9,3} & 48,6 \\
\hline & $20-40$ & 11,5 & 0,14 & 0,4 & 40 & 5,0 & 1 & & 24,9 & \multicolumn{2}{|c|}{8,1} & 37,0 \\
\hline
\end{tabular}

M.O. = Matéria orgânica; $\mathrm{SB}=$ Saturação de Bases; $\mathrm{CTC}=$ Capacidade de Troca Catiônica. 
sementes também foram tratadas com Fipronil (12 g i.a./100 kg sementes).

Durante a condução do experimento, os tratos fitossanitários em ambas as épocas de cultivo constituíram-se de duas aplicações de inseticidas (Lambda-Cialotrin $25 \mathrm{~g} \mathrm{ha}^{-1}$ de ingrediente ativo) e uma de herbicida (Atrazina $2.500 \mathrm{~g} \mathrm{ha}^{-1}$ de ingrediente ativo).

A adubação nitrogenada de cobertura foi dividida e aplicada nas fases fenológicas V3 e V8, utilizando a uréia como fonte de nitrogênio. Esta foi aplicada na fileira de plantas, junto às fitas gotejadoras, que foram acionadas após a adubação para minimizar as perdas por volatização. $\mathrm{Na}$ fase fenológica V3, foi realizada também a adubação potássica de cobertura com $80 \mathrm{~kg} \mathrm{ha}^{-1}$ de $\mathrm{K}_{2} \mathrm{O}$, utilizando cloreto de potássio (SOUSA; LOBATO, 2004).

O sistema de irrigação utilizado foi por gotejamento, por meio de fita gotejadora (mangueira gotejadora Petroisa). Os emissores (gotejadores) operaram com pressão de serviço de $98 \mathrm{kPa}$ aplicando vazão aproximada de $1,1 \mathrm{~L}$ $\mathrm{h}^{-1}$, e espaçados de $20 \mathrm{~cm}$ tendo uma fita para cada fileira de planta. A irrigação real necessária para o tratamento de $100 \%$ da ETc foi determinada em função de parâmetros das características do clima, planta e solo, representando a real necessidade de água do sistema (Equação 1).

$\mathrm{IRN}_{\mathrm{LOC}}=\sum_{\text {dial }}^{\mathrm{i}} \mathrm{ET}_{\mathrm{O}} \mathrm{K}_{\mathrm{C}} \mathrm{K}_{\mathrm{S}} \mathrm{K}_{\mathrm{L}}-\mathrm{P}_{\mathrm{E}}$

em que,

$\mathrm{IRN}_{\mathrm{LOC}}=$ irrigação real necessária em sistemas localizados (mm);

$\mathrm{ET}_{0}=$ evapotranspiração de referência $\left(\mathrm{mm} \mathrm{dia}^{-1}\right)$;

$\mathrm{K}_{\mathrm{C}}=$ coeficiente da cultura (adm);

$\mathrm{K}_{\mathrm{S}}=$ coeficiente de umidade do solo (adm)

$\mathrm{K}_{\mathrm{L}}=$ coeficiente de localização (adm); e

$\mathrm{P}_{\mathrm{E}}=$ precipitação efetiva no período $(\mathrm{mm})$.

Os dados meteorológicos diários utilizados no cálculo da evapotranspiração de referência $\left(\mathrm{ET}_{0}\right)$ foram retirados de uma estação meteorológica de superfície automática instalada próxima à área experimental. A metodologia de Penman-
Monteith-FAO56 foi utilizada para estimar a $\mathrm{ET}_{0}$. Os coeficientes de cultivo $\left(\mathrm{K}_{\mathrm{C}}\right)$ foram de 0,7 e 1,1 para os estádios I e III, respectivamente. Para o estádio II utilizou-se ponderação linear entre o final do estádio I e início do estádio III. A duração dos estádios I e II foi de 20 e 30 dias, respectivamente, e o estádio III do $50^{\circ}$ dia até a colheita. Os coeficientes de umidade do solo $\left(\mathrm{K}_{\mathrm{S}}\right)$ e de localização $\left(\mathrm{K}_{\mathrm{L}}\right)$ foram de acordo com Bernardo et al. (2006). Para aferição do manejo da irrigação por evapotranspiração, a umidade atual foi acompanhada por meio do potencial matricial da água no solo feito por tensiômetros digitais instalados nos tratamentos com lâmina de irrigação de $100 \%$ da ETc.

Ao atingirem a fase fenológica R3, foram realizadas a colheita das espigas. As colheitas foram realizadas nos dias 24/11/2012 e 31/5/2013 para as épocas de cultivo Inverno/Primavera e Verão/Outono, respectivamente. Estas foram realizadas nas primeiras horas da manhã, quando a umidade do ar ainda era alta e a temperatura era menor em relação aos outros momentos do dia, conforme as recomendações de Kwiatkowski e Clemente (2007).

Foram utilizadas dez espigas de plantas diferentes, escolhidas de forma aleatória dentro da área útil de cada parcela, seguindo a metodologia utilizada por Carmo et al. (2012), sendo avaliadas as seguintes características das espigas:

- Número de palhas por espiga (NPE): realizada no momento do despalhamento da espiga com a contagem no número de brácteas que envolvia a espiga;

- Comprimento de espiga (CE): determinado com auxílio de um escalímetro graduado em centímetros;

- Diâmetro de espiga (DE): medição da região central da espiga com auxílio de um paquímetro;

- Número de grãos por fileira (NGF): determinado pela média de grãos presentes em quatro fileiras de cada espiga;

- Número de fileiras por espiga (NFE): contagem do número de fileiras das espigas;

- Diâmetro de sabugo (DS): obtido pela medição por paquímetros do diâmetro de espiga, excluindo os grãos para a exposição correta do sabugo;

- Comprimento de grão (CG): subtraindo os 
raios do sabugo da medida dos raios das espigas;

- Número de grãos por espiga (NGE): determinado por meio da multiplicação do número de fileiras de grão pelo número de grãos por fileira;

- Peso de espiga (PE): determinado por meio da pesagem das espigas após a retirada da palha.

Os dados foram submetidos às análises de variância e regressão. A comparação de médias foi realizada usando-se o teste de Tukey a 5\% de significância. Para os fatores quantitativos, foram testados modelos lineares e quadráticos. A seleção do modelo foi com base na significância dos coeficientes de regressão, utilizando-se o teste $\mathrm{t} a$ $5 \%$ de significância, no coeficiente de determinação $\left(\mathrm{R}^{2}\right)$ e no fenômeno biológico. Para execução das análises estatísticas foram utilizados os softwares "Assistat 7.6" e "Sigmaplot 11.0".

\section{RESULTADOS E DISCUSSÃO}

A temperatura média diária do ar foi maior na primeira época de cultivo (Inverno/Primavera), alcançando um valor médio de $24,2^{\circ} \mathrm{C}$, variando dentro de uma amplitude de 15,4 a $29,5^{\circ} \mathrm{C}$ (Figura 1B). Na segunda época de cultivo (Verão/Outono), o valor médio foi de $22,3{ }^{\circ} \mathrm{C}$, oscilando entre 17,4 e $25,6^{\circ} \mathrm{C}$ (Figura 1B).

No período Inverno/Primavera, as precipitações pluviais concentraram no final do ciclo do milho doce apresentado um acumulado de $270,3 \mathrm{~mm}$, distribuídos em 23 eventos, com alturas variando de 2,6 a 54,0 mm (Figura 1A). Precipitações pluviométricas inferiores a $1 \mathrm{~mm}$ não foram consideradas, seguindo recomendações de Costa (1994), por entender que quantidade inferior a essa não atinge o solo, ficando retida na cobertura vegetal. No período Verão/Outono, as precipitações concentraram no início do ciclo do milho doce. A precipitação total na segunda época de cultivo foi de $342,6 \mathrm{~mm}$ (da semeadura a colheita), distribuídos em 34 eventos de chuva, com alturas variando entre 3,8 e 45,0 mm (Figura 1B).

O comportamento das chuvas, juntamente com a temperatura do ar, afetou a umidade relativa do ar.
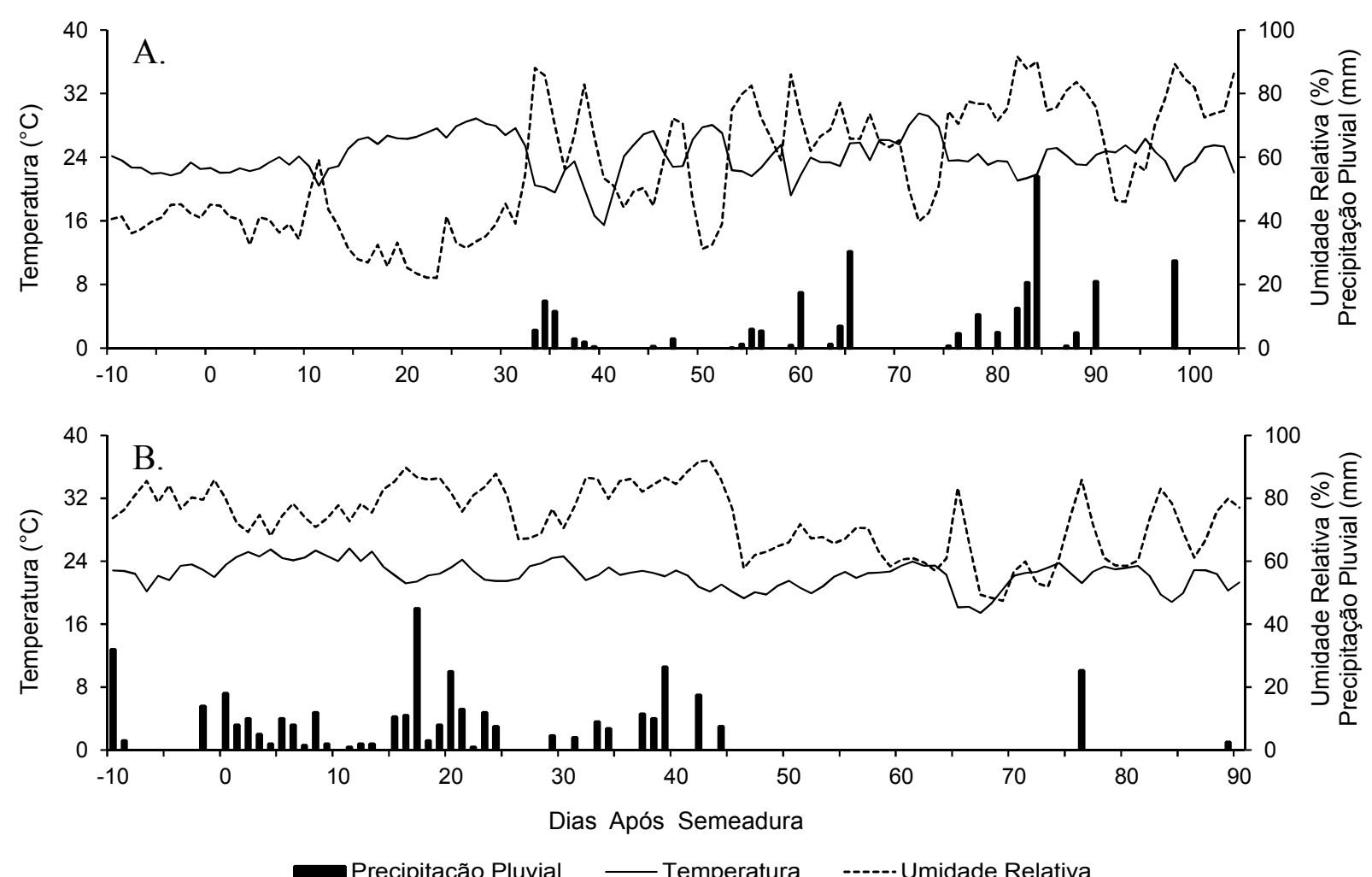

Figura 1. Variação diária da temperatura do ar $\left({ }^{\circ} \mathrm{C}\right)$, umidade relativa do ar (\%) e precipitação pluvial ( $\mathrm{mm}$ ), nas épocas de cultivo: (A) Inverno/Primavera e (B) Verão/Outono. O dia "0" na abscissa corresponde ao dia da semeadura. Chapadão do Sul - MS, UFMS-CPCS, 2012-2013.

54 REVENG $50-62 \mathrm{p}$. 
No período Inverno/Primavera, a umidade relativa variou entre 22,0 e 91,6\% (Figura 1A) e, no Verão/ Outono, entre 72,5 e $92,0 \%$ (Figura 1B).

Os valores de precipitação pluvial e de $\mathrm{ET}_{0}$ juntamente com outros parâmetros da cultura e do sistema de irrigação foram utilizados para o cálculo da lâmina de água aplicada, e no Quadro 2 estão apresentados os valores de irrigação real necessária e lâmina total de água em cada tratamento nos dois períodos de cultivo. A precipitação efetiva, segundo Bernardo et al. (2006), é aquela fração da precipitação utilizada diretamente pela cultura, ou seja, é a quantidade de água que a planta utiliza em seus processos fisiológicos. A diferença entre essa e a precipitação total foi a quantidade de água que escoou superficialmente e que percolou abaixo do sistema radicular da cultura, imediatamente após o solo ter atingido o teor de água acima ao equivalente à capacidade de campo. $\mathrm{Na}$ época Verão/Outono e no tratamento de lâmina de irrigação de $100 \%$ da ETc, por exemplo, dos 342,6 $\mathrm{mm}$ de água que atingiu o solo via precipitação pluvial, apenas 196,2 mm foi considerada efetiva $(57,3 \%)$, ou seja, que ficou disponível no solo para a cultura. Esse baixo aproveitamento foi devido à alta frequência de irrigação. Dessa forma, o solo sempre permaneceu próximo à capacidade de campo, sendo necessária baixa quantidade de água para atingir a capacidade total de armazenamento. Obteve-se maior precipitação efetiva no milho doce cultivado na época Inverno/Primavera. Esse resultado é devido às precipitações pluviais (Figura 1) terem concentradas em períodos que a cultura apresentava maiores valores de coeficiente de cultivo $\left(\mathrm{K}_{\mathrm{C}}\right)$ e de localização $\left(\mathrm{K}_{\mathrm{L}}\right)$, e diante disso, maior demanda evapotranspirométrica. No cultivo realizado no Verão/Outono, as chuvas coincidiram em períodos que o milho doce apresentava baixos valores de $\mathrm{K}_{\mathrm{C}}$ e $\mathrm{K}_{\mathrm{L}}$.

Observou-se maior consumo de água pelo milho doce cultivado na época Inverno/Primavera. Esse resultado foi alcançado devido a dois motivos principais, maior demanda evapotranspirométrica decorrente de maiores temperaturas e menores umidades relativas do ar (Figura 1) e maior ciclo da cultura nesse período. No cultivo conduzido na época Inverno/Primavera o ciclo da cultura foi de 99 dias, enquanto que no Verão/Outono de 90 dias. É oportuno ressaltar que as durações do ciclo do milho doce, nas duas épocas de cultivo, ficaram dentro do intervalo informado por sua detentora (Syngenta Seeds Ltda., 2015). Brito et al. (2013) cultivando milho doce no período de dezembro a fevereiro, em Pombal-PB, observaram consumo de $767,5 \mathrm{~mm}$ no tratamento irrigado com reposição de $100 \%$ da ETc. Esse maior consumo de água foi justificado pelas altas demandas evapotranspirométricas da região, com média de $6,9 \mathrm{~mm} \mathrm{dia}^{-1}$. Heinemann et al. (2001) relatam que a lâmina ótima de água para o milho doce cultivado em Sete Lagoas-MG é de $385 \mathrm{~mm}$. Nos Estados Unidos da América, Garcia et al. (2009) verificaram que o milho doce consumiu $343 \mathrm{~mm}$ de água cultivado no Inverno e $260 \mathrm{~mm}$ na Primavera.

No Quadro 3 estão apresentadas as análises de variância dos parâmetros analisados. Verificou-se que o número de palha por espiga sofreu variação isolada das épocas de cultivo. A época de cultivo Verão/Outono proporcionou maior número de palha por espiga do milho doce (Quadro 4).

Quadro 2. Precipitação efetiva (PE), irrigação real necessária (IRN) e lâmina de água total (LAT) aplicada em cada tratamento e época de cultivo. Chapadão do Sul - MS, UFMS-CPCS, 2012-2013.

\begin{tabular}{cccccc}
\hline \multirow{2}{*}{ Época } & \multirow{2}{*}{ Evento } & \multicolumn{4}{c}{ Lâminas de Irrigação (\% ETc) } \\
\cline { 3 - 6 } & & $50 \%$ & $75 \%$ & $100 \%$ & $125 \%$ \\
\hline \multirow{2}{*}{ Inverno/ } & PE (mm) & 258,8 & 220,6 & 185,1 & 185,1 \\
Primavera & IRN (mm) & 111,3 & 167,0 & 222,7 & 278,4 \\
& LAT (mm) & 370,1 & 387,7 & 407,8 & 463,4 \\
\hline \multirow{2}{*}{ Verão/ } & PE (mm) & 213,7 & 208,6 & 196,2 & 196,2 \\
Outono & IRN (mm) & 64,5 & 96,8 & 129,1 & 161,3 \\
& LAT (mm) & 278,3 & 305,4 & 325,3 & 357,6 \\
\hline
\end{tabular}


Quadro 3. Análises de variância de número de palha por espiga (NPE), comprimento de espiga (CE), diâmetro de espiga (DE), número de grãos por fileira (NGF), número de fileiras por espiga (NFE), diâmetro de sabugo (DS), comprimento de grão (CG), número de grãos por espiga (NGE) e peso de espiga (PE). Chapadão do Sul - MS, UFMS-CPCS, 2012-2013.

\begin{tabular}{|c|c|c|c|c|c|c|c|c|c|c|}
\hline \multirow{2}{*}{ FV } & \multirow{2}{*}{ GL } & \multicolumn{9}{|c|}{ Quadrado Médio } \\
\hline & & NPE & $\mathrm{CE}$ & $\mathrm{DE}$ & NGF & NFE & DS & $\mathrm{CG}$ & NGE & PE \\
\hline Bloco & 3 & $1,5 \mathrm{E}+0^{\mathrm{ns}}$ & $2,4 \mathrm{E}+0^{\text {ns }}$ & $1,4 \mathrm{E}+1^{*}$ & $5,1 \mathrm{E}+0^{*}$ & $5,9 \mathrm{E}+0^{* *}$ & $6,8 \mathrm{E}-1^{\mathrm{ns}}$ & $2,5 \mathrm{E}+0^{\mathrm{ns}}$ & $3,0 \mathrm{E}+4^{* *}$ & $1,8 \mathrm{E}-3^{\mathrm{ns}}$ \\
\hline LI & 3 & $5,2 \mathrm{E}+0^{* *}$ & $4,6 \mathrm{E}+0^{\mathrm{ns}}$ & $4,9 \mathrm{E}+0^{\mathrm{ns}}$ & $1,3 \mathrm{E}+1^{\mathrm{ns}}$ & $5,7 \mathrm{E}-1^{\mathrm{ns}}$ & $1,2 \mathrm{E}+0^{\mathrm{ns}}$ & $4,6 \mathrm{E}-1^{\mathrm{ns}}$ & $4,4 \mathrm{E}+3^{\mathrm{ns}}$ & $5,2 \mathrm{E}-3^{\mathrm{ns}}$ \\
\hline Resíduo (A) & 9 & $5,3 \mathrm{E}-1$ & $2,9 \mathrm{E}+5$ & $2,3 \mathrm{E}+5$ & $9,2 \mathrm{E}+0$ & $5,6 \mathrm{E}-1$ & $1,2 \mathrm{E}+0$ & $7,5 \mathrm{E}-1$ & $4,1 \mathrm{E}+3$ & $2,2 \mathrm{E}-3$ \\
\hline $\mathrm{DN}$ & 3 & $7,6 \mathrm{E}-2^{\mathrm{ns}}$ & $1,1 \mathrm{E}+0^{\mathrm{ns}}$ & $4,0 \mathrm{E}+0^{\mathrm{ns}}$ & $1,2 \mathrm{E}+1^{\mathrm{ns}}$ & $1,5 \mathrm{E}+0^{\mathrm{ns}}$ & $2,2 \mathrm{E}+0^{\mathrm{ns}}$ & $1,7 \mathrm{E}-1^{\mathrm{ns}}$ & $4,8 \mathrm{E}+3^{\mathrm{ns}}$ & $5,6 \mathrm{E}-3^{* *}$ \\
\hline LI x DN & 9 & $4,1 \mathrm{E}-1^{\mathrm{ns}}$ & $6,0 \mathrm{E}-1^{\mathrm{ns}}$ & $2,6 \mathrm{E}+0^{\mathrm{ns}}$ & $1,4 \mathrm{E}+1^{\mathrm{ns}}$ & $1,0 \mathrm{E}+0^{\mathrm{ns}}$ & $7,7 \mathrm{E}-1^{\mathrm{ns}}$ & $5,4 \mathrm{E}-1^{\mathrm{ns}}$ & $5,8 \mathrm{E}+3^{\mathrm{ns}}$ & $1,2 \mathrm{E}-3^{\mathrm{ns}}$ \\
\hline Resíduo (B) & 36 & $4,2 \mathrm{E}-1$ & $9,6 \mathrm{E}-1$ & $2,0 \mathrm{E}+5$ & $9,5 \mathrm{E}+0$ & $6,1 \mathrm{E}-1$ & $1,2 \mathrm{E}+0$ & $4,4 \mathrm{E}-1$ & $3,4 \mathrm{E}+3$ & $9,8 \mathrm{E}-4$ \\
\hline $\mathrm{EC}$ & 1 & $9,1 \mathrm{E}+5^{* *}$ & $2,1 \mathrm{E}+2^{* *}$ & $1,6 \mathrm{E}+1^{* *}$ & $1,7 \mathrm{E}+2^{* *}$ & $4,6 \mathrm{E}-2^{\mathrm{ns}}$ & $1,3 \mathrm{E}+0^{\mathrm{ns}}$ & $6,6 \mathrm{E}+0^{* *}$ & $3,5 \mathrm{E}+4^{* *}$ & $5,7 \mathrm{E}-4^{\mathrm{ns}}$ \\
\hline $\mathrm{LI} \times \mathrm{EC}$ & 3 & $6,3 \mathrm{E}-1^{\mathrm{ns}}$ & $3,0 \mathrm{E}+0^{*}$ & $9,0 \mathrm{E} 1^{\mathrm{ns}}$ & $1,5 \mathrm{E}+1^{\mathrm{ns}}$ & $3,1 \mathrm{E}-1^{\mathrm{ns}}$ & $3,0 \mathrm{E}+0^{\mathrm{ns}}$ & $5,4 \mathrm{E}-1^{\mathrm{ns}}$ & $5,4 \mathrm{E}+3^{\mathrm{ns}}$ & $2,1 \mathrm{E}-3^{\mathrm{ns}}$ \\
\hline $\mathrm{DN} \times \mathrm{EC}$ & 3 & $9,7 \mathrm{E}-2^{\mathrm{ns}}$ & $1,3 \mathrm{E}+0^{\mathrm{ns}}$ & $2,0 \mathrm{E}+0^{\mathrm{ns}}$ & $2,4 \mathrm{E}+0^{\mathrm{ns}}$ & $3,6 \mathrm{E}-1^{\mathrm{ns}}$ & $2,4 \mathrm{E}-1^{\mathrm{ns}}$ & $4,6 \mathrm{E}-1^{\mathrm{ns}}$ & $1,1 \mathrm{E}+3^{\mathrm{ns}}$ & $2,2 \mathrm{E}-3^{\mathrm{ns}}$ \\
\hline $\mathrm{LI} \times \mathrm{DN} \times \mathrm{EC}$ & 9 & $3,4 \mathrm{E}-1^{\mathrm{ns}}$ & $8,1 \mathrm{E}-1^{\mathrm{ns}}$ & $9,5 \mathrm{E}-1^{\mathrm{ns}}$ & $4,1 \mathrm{E}+0^{\mathrm{ns}}$ & $1,1 \mathrm{E}+0^{\mathrm{ns}}$ & $2,6 \mathrm{E}+0^{\mathrm{ns}}$ & $3,4 \mathrm{E}-1^{\mathrm{ns}}$ & $2,0 \mathrm{E}+3^{\mathrm{ns}}$ & $7,2 \mathrm{E}-4^{\mathrm{ns}}$ \\
\hline Resíduo (C) & 48 & $6,1 \mathrm{E}-1$ & $9,4 \mathrm{E}-1$ & $1,1 \mathrm{E}+5$ & $8,4 \mathrm{E}+0$ & $6,2 \mathrm{E}-1$ & $1,8 \mathrm{E}+0$ & $4,6 \mathrm{E}-1$ & $2,8 \mathrm{E}+3$ & $1,6 \mathrm{E}-3$ \\
\hline \multicolumn{2}{|l|}{ CV(\%) Parcela } & 8,42 & 9,68 & 3,25 & 10,18 & 5,01 & 4,13 & 8,51 & 14,24 & 20,99 \\
\hline \multicolumn{2}{|c|}{ CV(\%) Sub-parcela } & 7,49 & 5,56 & 3,07 & 10,31 & 5,24 & 4,26 & 6,55 & 12,98 & 13,90 \\
\hline \multicolumn{2}{|c|}{ CV(\%) Sub-subparcela } & 9,07 & 5,52 & 2,30 & 9,70 & 5,27 & 5,12 & 6,69 & 11,87 & 17,64 \\
\hline
\end{tabular}

LI = Lâmina de Irrigação; DN = Dose Nitrogenada; EC = Época de Cultivo; ${ }^{*} p<0,05 ;{ }^{* *} p<0,01 ;{ }^{\text {ns }} p>0,05$.

Quadro 4. Valores médios de número de palha por espiga (NPE), comprimento de espiga (CE), diâmetro de espiga (DE), número de grãos por fileira (NGF), comprimento de grão $(\mathrm{CG})$ e número de grãos por espiga (NGE) em função das lâminas de irrigação e épocas de cultivo. Chapadão do Sul - MS, UFMS-CPCS, 2012-2013.

\begin{tabular}{|c|c|c|c|c|c|c|}
\hline \multirow{2}{*}{ Parâmetro } & \multirow{2}{*}{ Época } & \multirow{2}{*}{$\mathrm{dms}$} & \multicolumn{4}{|c|}{ Lâminas de Irrigação (\% ETc) } \\
\hline & & & $50 \%$ & $75 \%$ & $100 \%$ & $125 \%$ \\
\hline \multirow[t]{2}{*}{ NPE } & Inv/Pri & \multirow{2}{*}{0,28} & \multicolumn{4}{|c|}{$8,38 \mathrm{~b}$} \\
\hline & Ver/Out & & \multicolumn{4}{|c|}{$8,90 \mathrm{a}$} \\
\hline \multirow{2}{*}{$\begin{array}{c}\mathrm{CE} \\
(\mathrm{cm})\end{array}$} & Inv/Pri & \multirow{2}{*}{0,69} & $19,10 \mathrm{a}$ & 18,39 a & $19,74 \mathrm{a}$ & $18,30 \mathrm{a}$ \\
\hline & Ver/Out & & $16,27 \mathrm{~b}$ & $16,38 \mathrm{~b}$ & $16,43 \mathrm{~b}$ & $16,16 b$ \\
\hline \multirow{2}{*}{$\begin{array}{c}\mathrm{DE} \\
(\mathrm{mm})\end{array}$} & Inv/Pri & \multirow{2}{*}{0,38} & \multicolumn{4}{|c|}{$46,02 \mathrm{~b}$} \\
\hline & Ver/Out & & \multicolumn{4}{|c|}{$46,73 \mathrm{a}$} \\
\hline \multirow[t]{2}{*}{ NGF } & Inv/Pri & \multirow{2}{*}{1,03} & \multicolumn{4}{|c|}{$31,01 \mathrm{a}$} \\
\hline & Ver/Out & & \multicolumn{4}{|c|}{$28,73 \mathrm{~b}$} \\
\hline \multirow{2}{*}{$\begin{array}{c}\mathrm{CG} \\
(\mathrm{mm})\end{array}$} & Inv/Pri & \multirow{2}{*}{0,24} & \multicolumn{4}{|c|}{$9,95 \mathrm{~b}$} \\
\hline & Ver/Out & & \multicolumn{4}{|c|}{$10,40 \mathrm{a}$} \\
\hline \multirow[t]{2}{*}{ NGE } & Inv/Pri & \multirow{2}{*}{18,90} & \multicolumn{4}{|c|}{$464,02 \mathrm{a}$} \\
\hline & Ver/Out & & \multicolumn{4}{|c|}{$431,08 \mathrm{~b}$} \\
\hline
\end{tabular}

$\mathrm{dms}=$ diferença mínima significativa; Médias seguidas de mesma letra nas colunas não diferem entre si pelo teste de Tukey $(p<0,05)$. 
Do ponto de vista da qualidade de espiga, o empalhamento é uma característica que pode afetar tanto a qualidade dos grãos quanto o rendimento industrial. Segundo Albuquerque et al. (2008), em espigas bem empalhadas, verifica-se menor susceptibilidade ao ataque de pragas, além de auxiliar na conservação das mesmas. Okumura et al. (2013) relatam que número de palha acima de 14 prejudica o rendimento industrial da espiga do milho doce, entretanto, segundo Sawazaki et al. (1990), número de palha inferir a 7 favorece o ataque de pragas. Diante disso, apesar das épocas proporcionarem diferença nessa característica, as duas épocas de cultivo apresentaram valores dentro do intervalo supracitado.

O comprimento de espiga apresentou interação entre lâminas de irrigação e épocas de cultivo na análise de variância (Quadro 3). O milho doce cultivado na época Inverno/Primavera apresentou maior comprimento de espiga em relação ao cultivado na época Verão/Outono, independente da lâmina de irrigação aplicada (Quadro 4). A diferença do comprimento de espiga pode estar relacionada a variação de temperatura do ar ocorrida nas épocas de cultivo. Segundo Carmo et al. (2012), a ocorrência de temperaturas elevadas, principalmente durante as fases de florescimento e início de enchimento de grãos, acelera as taxas de desenvolvimento das estruturas reprodutivas da planta. Durante estas fases, as temperaturas médias diárias do ar no Inverno/Primavera foram mais elevadas em relação à outra época de cultivo (Figura 1). Os valores de comprimento de espiga em todos os tratamentos variaram dentro do intervalo de 16,16 e 19,74 cm, ficando dentro dos padrões aceitáveis. De acordo com Albuquerque et al. (2008), espigas de milho doce com comprimento superior a $15 \mathrm{~cm}$ é uma característica indispensável para sua comercialização.

$\mathrm{Na}$ análise do diâmetro de espiga do milho doce, verificou-se efeito isolado das épocas de cultivo (Quadro 3). O milho doce cultivado na época Verão/Outono apresentou maiores valores de diâmetro de espiga (Quadro 4). Um fator que contribuiu para esse resultado foi o maior número de palha por espiga na mesma época de cultivo.

As épocas de cultivo do milho doce proporcionaram efeito no número de grãos por fileira (Quadro 3). Verificou-se maior número de grãos por fileira na época de cultivo Inverno/Primavera (Quadro 4). Esse resultado possivelmente pode ser creditado nos maiores valores médios diários de temperatura do ar verificados nessa mesma época de cultivo (Figura 1). Segundo Didonet et al. (2002) esse elemento meteorológico tem efeito positivo no número de grão.

Os parâmetros número de fileiras por espiga e diâmetro de sabugo do milho doce não foram afetados por nenhum fator na análise de variância (Quadro 3). Esperava-se maior número de fileiras por espiga no Verão/Outono, como observado para o diâmetro de espiga. Isso não confirmou principalmente pela baixa diferença do diâmetro de espiga (1,5\%) entre os dois cultivos.

As épocas de cultivo apresentaram efeito isolado sobre o comprimento de grão (Quadro 3). Os grãos do milho cultivando na época Verão/Outono apresentaram maior comprimento (Quadro 4).

$\mathrm{O}$ número de grãos por espiga do milho doce sofreu efeito isolado das épocas de cultivo (Quadro 3 ), em que observou maiores valores na época Inverno/Primavera (Quadro 4). Este efeito pode ser explicado pela ação da temperatura do ar (Figura 1), anteriormente reportado por Didonet et al. (2002).

As épocas climáticas não proporcionaram efeito no peso de espiga de milho doce (Quadro 3). Esse resultado possivelmente pode ser justificado pelo uso de irrigação nos dois períodos experimentais. Farinelli et al. (2003) avaliando 15 cultivares de milho de sequeiro em duas épocas em Jaboticabal$\mathrm{SP}$, verificaram que o milho colhido no Verão apresentou, em média, valor $11,8 \%$ superior ao colhido no Inverno.

Independente da época de cultivo, não foi possível ajustar equação de regressão para os parâmetros número de fileiras por espiga, diâmetro de sabugo e comprimento de grão em função das lâminas de irrigação e doses nitrogenadas. As lâminas de irrigação proporcionaram efeito linear negativo no número de palha por espiga do milho doce nas duas épocas avaliadas (Figura 2 e 3). Presume-se que a planta, quando submetida à redução da disponibilidade hídrica sofre um aumento no número de palha por espiga, visando aumentar a proteção do grão, para que assim possa garantir perpetuação e proliferação da espécie. No entanto, esta variação do número de palha por espiga em reação as lâminas de irrigação testadas não chegaram a comprometer os padrões de qualidade da espiga. O número de palha acima de 14 prejudica o rendimento industrial da espiga (OKUMURA et al., 2013), entretanto, o número de palha inferindo a 7 favorece o ataque de pragas (SAWAZAKI et al., 1990). 

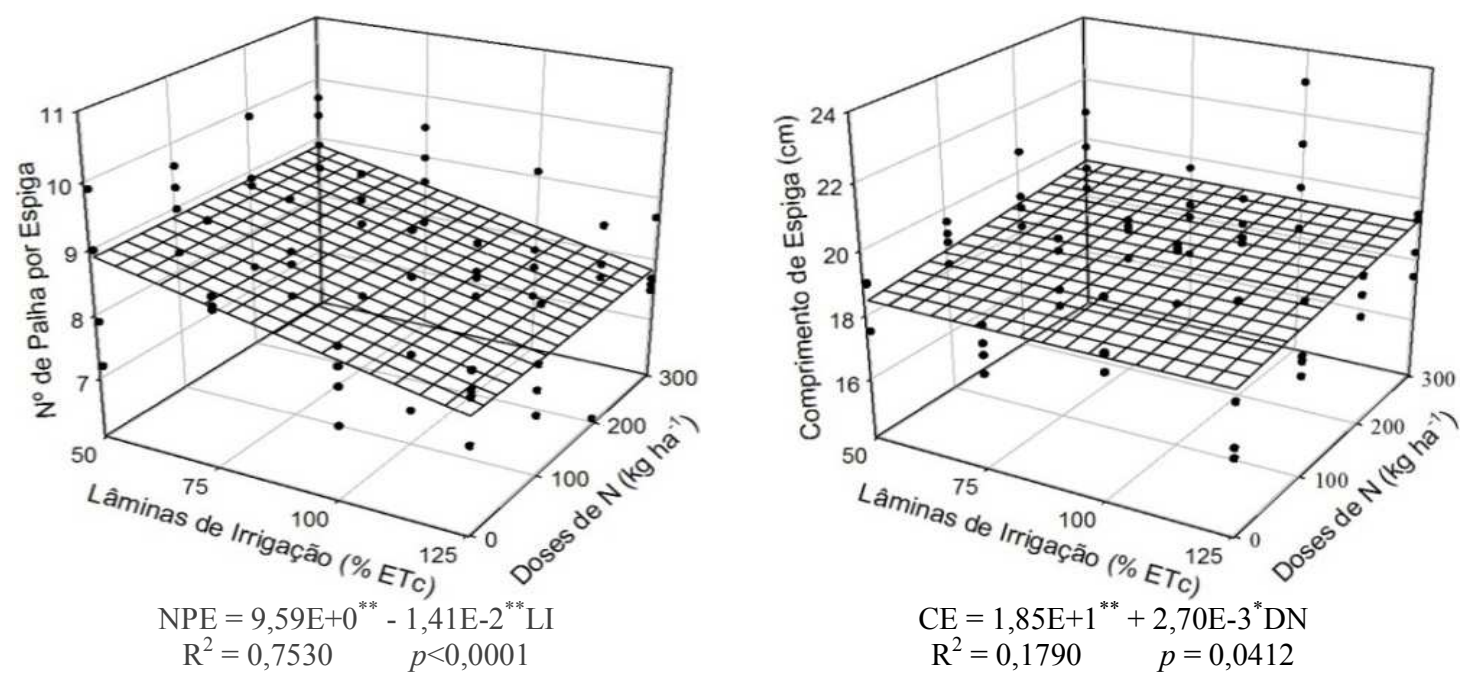

$$
\mathrm{CE}=1,85 \mathrm{E}+1^{* *}+2,70 \mathrm{E}-3^{*} \mathrm{DN}
$$

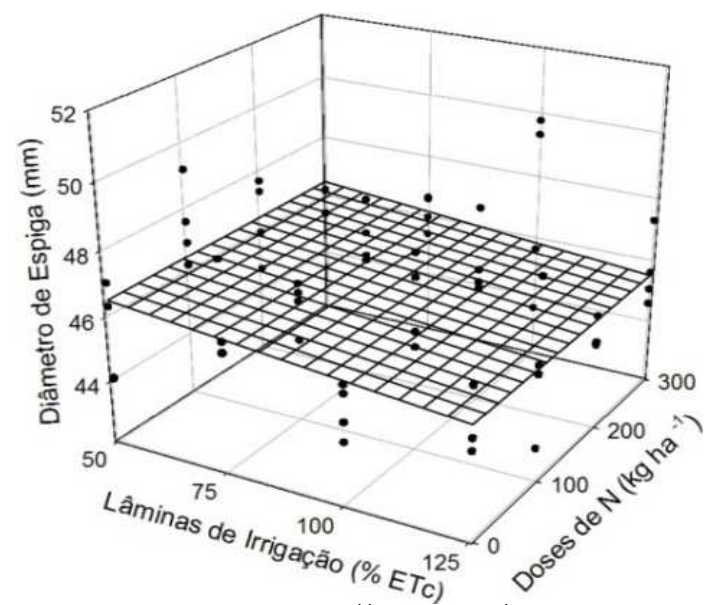

$\mathrm{DE}=4,72 \mathrm{E}+1^{* *}-1,31 \mathrm{E}-2^{*} \mathrm{LI}$

$\mathrm{R}^{2}=0,2100 \quad p=0,0484$

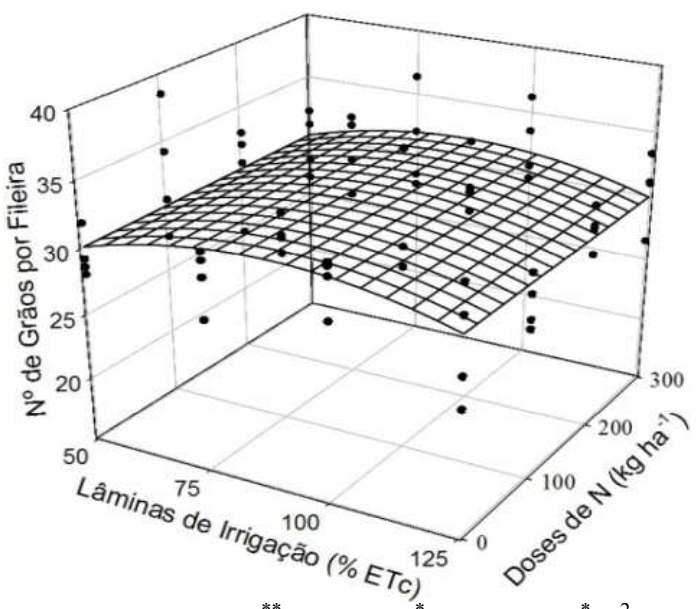

$\mathrm{NGF}=2,12 \mathrm{E}+1^{* *}+2,53 \mathrm{E}-1^{*} \mathrm{LI}-1,50 \mathrm{E}-3^{*} \mathrm{LI}^{2}$ $\mathrm{R}^{2}=0,2887 \quad p=0,0741$

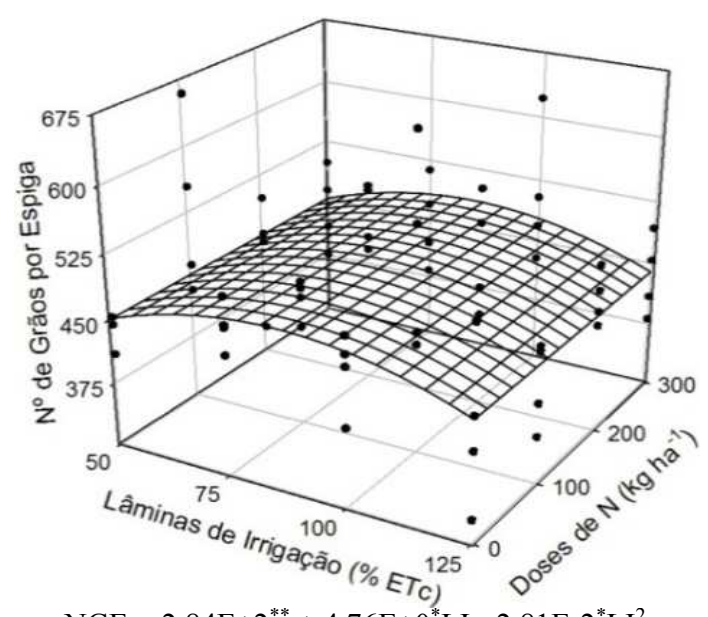

$\mathrm{NGE}=2,84 \mathrm{E}+2^{* *}+4,76 \mathrm{E}+0^{*} \mathrm{LI}-2,81 \mathrm{E}-2^{*} \mathrm{LI}^{2}$ $\mathrm{R}^{2}=0,2698 \quad p=0,0876$

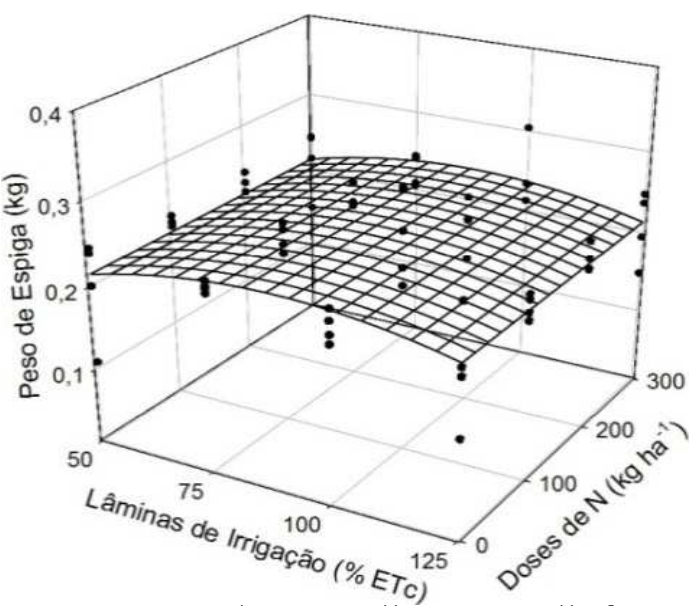

$\mathrm{PE}=9,92 \mathrm{E}-2^{*}+3,30 \mathrm{E}-3^{* *} \mathrm{LI}-1,88 \mathrm{E}-5^{* *} \mathrm{LI}^{2}$ $\mathrm{R}^{2}=0,3379 \quad p=0,0248$

$$
{ }^{*} p<0,05 ;{ }^{* *} p<0,01
$$

Figura 2. Estimativa do número de palha por espiga (NPE), comprimento de espiga (CE), diâmetro de espiga (DE), número de grãos por fileira (NGF), número de grãos por espiga (NGE) e peso de espiga (PE) em função das lâminas de irrigação (LI) e doses nitrogenadas (DN) na época de cultivo Inverno/Primavera. Chapadão do Sul - MS, UFMS-CPCS, 2012-2013.

58 REVENG 

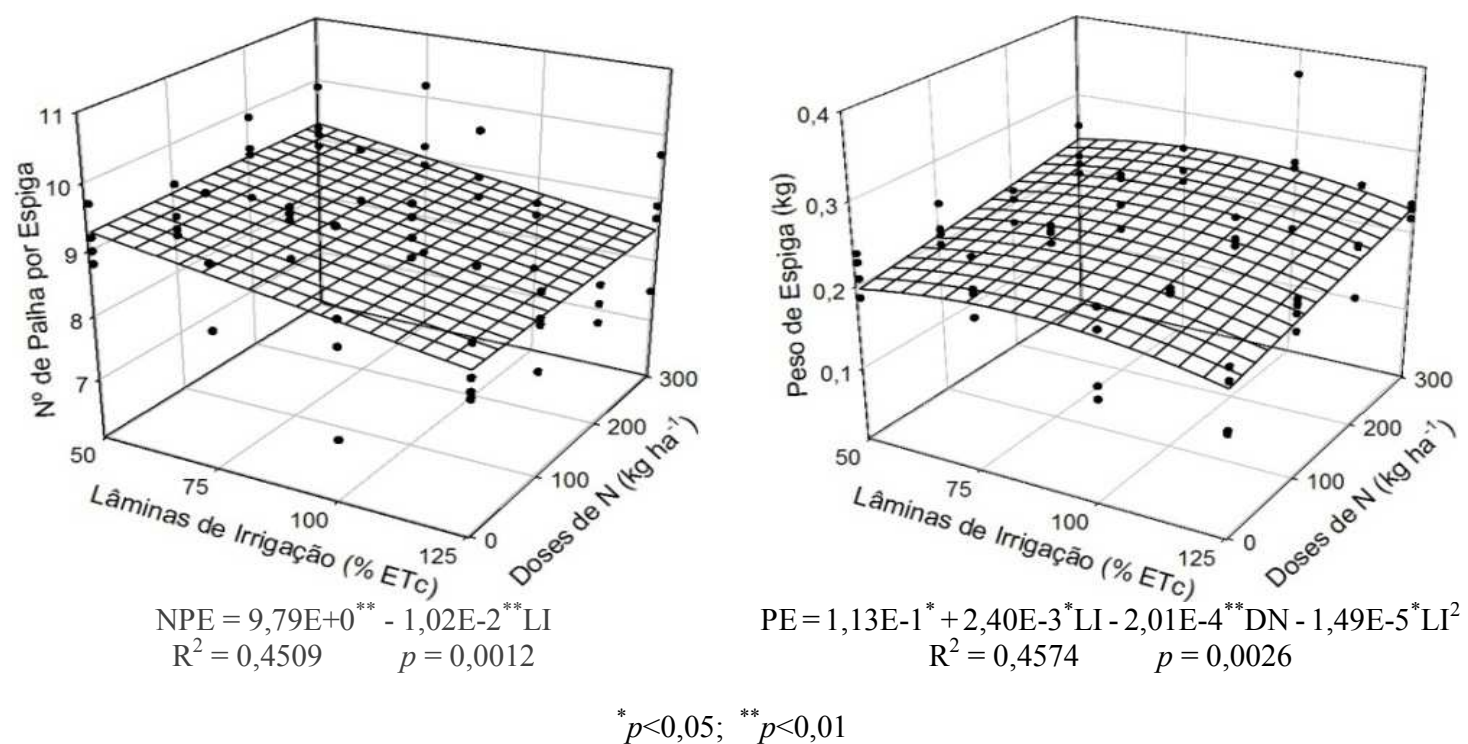

Figura 3. Estimativa do número de palha por espiga (NPE) e peso de espiga (PE) em função das lâminas de irrigação (LI) e doses nitrogenadas (DN) na época de cultivo Verão/Outono. Chapadão do Sul - MS, UFMS-CPCS, 2012-2013.

As lâminas de irrigação, independente da época de cultivo, não afetaram o comprimento da espiga do milho doce (Figuras 2 e 3). Esse resultado corrobora com Ferreira et al. (2011) trabalhando com milho doce em Pombal-PB, e diverge de outras pesquisas na literatura. Blanco et al. (2011) avaliando lâminas de irrigação e doses de fósforo em milho verde consorciado com feijão-caupi em Teresina-PI, observaram efeito linear positivo no comprimento de espiga em função das lâminas de irrigação. Segundo Souza e Soratto (2006), o estresse hídrico durante a fase reprodutiva do milho limita o desenvolvimento da espiga, altera a sincronia entre o florescimento masculino e feminino, justificando assim o efeito das lâminas de irrigação. Esse resultado não foi alcançado na presente pesquisa, possivelmente pelas precipitações pluviais ocorridas na fase de florescimento nas duas épocas de cultivo (Figura 1).

As doses de nitrogênio proporcionaram efeito linear positivo no comprimento de espiga na época de cultivo Inverno/Primavera (Figura 2). Este resultado corrobora com Khazaei e Aghaalikhani (2011) no Irã e Carmo et al. (2012) em Palmeiras de Goiás-GO, ambos avaliando o efeito de doses de nitrogênio no comprimento de espiga do milho doce.
O diâmetro de espiga sofreu efeito linear negativo em função das lâminas de irrigação na época de cultivo Inverno/Primavera (Figura 2). Apesar desse resultado, o diâmetro de espiga ficou acima dos valores recomendados para sua comercialização, que são acima de $30 \mathrm{~mm}$ conforme Albuquerque et al. (2008). Diante disso, pode-se afirmar que as lâminas de irrigação não prejudicam esse parâmetro da espiga do milho doce.

As doses de nitrogênio não influenciaram o diâmetro da espiga do milho doce (Figura 2), corroborando com Aguiar et al. (2012) testando diferentes doses de $\mathrm{N}$ em milho verde cultivado em Gurupi-TO. Resultado oposto foi encontrado por Freire et al. (2010), que observaram comportamento quadrático testando doses variando entre 0 e 240 $\mathrm{kg} \mathrm{ha}^{-1}$ de $\mathrm{N}$ em milho cultivado em Prudente de Morais-MG. Esses autores verificaram que o aumento do diâmetro de espiga foi expressivo somente até a dose de $60 \mathrm{~kg} \mathrm{ha}^{-1}$.

As lâminas de irrigação conferiram efeito quadrático ao número de grãos por fileiras do milho doce cultivado na época Inverno/Primavera (Figura 2). Derivando a equação de regressão, o número máximo de grãos por fileira foi obtido aplicando a lâmina de irrigação de $84,2 \%$ da ETc, resultando no valor máximo de 32 grãos por fileira.

A adubação nitrogenada não conferiu efeito 
no número de grãos por fileira da espiga do milho doce em nenhuma época de cultivo (Figuras $2 \mathrm{e}$ 3). Biscaro et al. (2011) aplicando adubações de duas formas e com doses crescentes de $\mathrm{N}$ em milho safrinha e irrigado em Dourados-MS, observaram comportamento quadrático, onde as doses de 290 e $360 \mathrm{~kg} \mathrm{ha}^{-1}$ de $\mathrm{N}$ aplicadas via solo e foliar, respectivamente, maximizaram o número de grãos por espiga.

O número de grãos por espiga do milho doce (Figura 2) apresentou o mesmo comportamento que o número de grãos por fileira (Figura 2) em resposta as lâminas de irrigação e adubação nitrogenada na época Inverno/Primavera. Esses parâmetros são altamente correlacionáveis e o número de grãos por espiga apresentou comportamento quadrático em função das lâminas de irrigação, em que o máximo valor retirado da equação de regressão foi de 487 grãos, correspondente a aplicação da lâmina de irrigação de $84,7 \%$ da ETc. Ferreira et al. (2011) estudando lâminas de irrigação em função da ETc em milho doce cultivado em Pombal-PB, encontraram resultados próximos aos anteriormente citado, porém não foi possível determinar a lâmina ótima de irrigação para esta característica. De acordo com Carmo et al. (2012), dentre os componentes de produção, o número de grãos por espiga é o parâmetro que mais está associado ao rendimento de milho doce.

As lâminas de irrigação proporcionaram efeito quadrático no peso de espiga de milho doce cultivado no Inverno/Primavera (Figura 2). De acordo com a equação de regressão, a lâmina de irrigação que maximizou o peso de espiga foi de $87,8 \%$ da ETc, resultando no valor máximo de 244 g. Nessa mesma época de cultivo, as lâminas de irrigação que potencializaram outros parâmetros importantes como número de grãos por fileira e por espiga, foram de 84,2 e $84,7 \%$ da ETc, respectivamente. Diante disso, recomenda-se na época Inverno/Primavera, irrigar o milho doce com reposição de $85 \%$ da ETc.

No Verão/Outono, a lâmina de irrigação que maximizou o peso de espiga foi de $80,5 \%$ da ETc. Entretanto, os demais parâmetros analisados não foram afetados pelas lâminas de irrigação, e diante disso, sugere-se que o milho doce cultivado na época Verão/Outono seja irrigado com lâmina para repor $50 \%$ da ETc, garantindo economia de água e energia elétrica.

Quanto às doses nitrogenadas (Figuras 2 e 3), independente da época de cultivo, não foi verificado efeito no peso de espiga. Este comportamento das doses de nitrogênio abaixo do esperado sobre alguns parâmetros estudados sugere uma possível explicação apresentada por Costa et al. (2008), que afirmam que esta situação ocorre em virtude de níveis inadequados de potássio, devido a interação entre a absorção e o aproveitamento desses dois macronutrientes. Esta hipótese levantada é reforçada pelo fato de não ter havido suplementação de potássio proporcional às doses de nitrogênio, a fim de equilibrar a interação entre estes dois elementos. Esta interação está relacionada com atividade da enzima redutase do nitrato, enzima que atua na incorporação do nitrogênio inorgânico (SILVA et al., 2011). Esse fato pode ser confirmado pela redução do potássio, apresentado na análise química do solo (Quadro 1), ocorrida entre os dois cultivos.

\section{CONCLUSÕES}

Diante dos resultados, concluiu-se que:

- O milho doce apresenta maior peso e qualidade de espigas quando cultivado na época Verão/ Outono;

- Na época Inverno/Primavera, o milho doce deve ser irrigado com reposição de $85 \%$ da ETc, enquanto que no Verão/Outono, com 50\% da ETc;

- A adubação nitrogenada não afeta a qualidade de espiga.

\section{AGRADECIMENTOS}

À Coordenação de Aperfeiçoamento de Pessoal de Nível Superior (Capes), pela concessão da bolsa de mestrado a primeira autoria, a Syngenta Seeds LTDA pela doação das sementes, ao Grupo Feltre pela doação das cápsulas porosa dos tensímetros e a Fundação Chapadão pelo apoio no fornecimento de produtos para a condução da pesquisa. 


\section{REFERÊNCIAS BIBLIOGRÁFICAS}

AGUIAR, C.B.N.; COIMBRA, R.R.; AFERRI, F.S.; PAULA, M.J.; FREITAS, M.K.C.; OLIVEIRA, R.J. Desempenho agronômico de híbridos de milho verde em função da adubação nitrogenada de cobertura. Revista de Ciências Agrárias, Belém, v.55, n.1, p.11-16, 2012.

ALBUQUERQUE, C.J.B.; PINHO, R.G.V.; SILVA, R. Produtividade de híbridos de milho verde experimentais e comerciais. Bioscience Journal, Uberlândia, v.24, n.2, p.69-76, 2008.

BERNARDO, S.; SOARES, A.A.; MANTOVANI, E.C. Manual de irrigação. 8.ed. Viçosa: UFV, 2006, 625p.

BISCARO, G.A.; MOTOMIYA, A.V.A.; RANZI, R.; VAZ, M.A.B.; PRADO, E.A.F.; SILVEIRA, B.L.R. Desempenho do milho safrinha irrigado submetido a diferentes doses de nitrogênio via solo e foliar. Agrarian, Dourados, v.4, n.11, p.10-19, 2011.

BLANCO, F.F.; CARDOSO, M.J.; FREIRE FILHO, F.R.; VELOSO, M.E.C.; NOGUEIRA, C.C.P.; DIAS, N.S. Milho verde e feijão-caupi cultivados em consórcio sob diferentes lâminas de irrigação e doses de fósforo. Pesquisa Agropecuária Brasileira, Brasília, v.46, n.5, p.524-530, 2011.

BORIN, A.L.D.C.; LANA, R.M.Q.; PEREIRA, H.S. Absorção, acúmulo e exportação de macronutrientes no milho doce cultivado em condições de campo. Ciência e Agrotecnologia, Lavras, v.34, Edição Especial, p.1591-1597, 2010.

BRITO, M.E.B.; ARAÚJO FILHO, G.D.; WANDERLEY, J.A.C.; MELO, A.S.; COSTA, F.B.; FERREIRA, M.G.P. Crescimento, fisiologia e produção do milho doce sob estresse hídrico. Bioscience Journal, Uberlândia, v.29, n.5, p.12441253, 2013.

CARMO, M.S.; CRUZ, S.C.S.; SOUZA, E.J.; CAMPOS, L.F.C.; MACHADO, C.G. Doses e fontes de nitrogênio no desenvolvimento e produtividade da cultura de milho doce (Zea mays convar. saccharata var. rugosa). Bioscience Journal, Uberlândia, v.28, sup.1, p.223-231, 2012.

CASTRO, M.A.; CUNHA, F.F.; LIMA, S.F.; PAIVA NETO, V.B.; LEITE, A.P.; MAGALHAES, F.F.; CRUZ, G.H.M. Atributos fisico-hidricos do solo ocupado com pastagem degradada e floresta nativa no cerrado Sul-Mato-Grossense. Brazilian Geographical Journal, Ituiutaba, v.3, n.2, p.498512, 2012.

COSTA, K.A.P.; ARAUJO, J.L.; FRANQUIN, V.; OLIVEIRA, I.P.; FIGUEIREDO, F.C.; GOMES, K.W. Extração de macronutrientes pela fitomassa do capim-xaraés em função de doses de nitrogênio e potássio. Ciência Rural, Santa Maria, v.38, n.4, p.1162-1166, 2008.

COSTA, M.H. Análise de dados de precipitação. Viçosa: AEAMG, 1994. 21p.

DIDONET, A.D.; RODRIGUES, O.; MARIO, J.L.; IDE, F. Efeito da radiação solar e temperatura na definição do número de grãos em milho. Pesquisa Agropecuária Brasileira, Brasília, v.37, n.7, p.933-938, 2002.

FARINELLI, R.; LEMOS, L.B. Produtividade e eficiência agronômica do milho em função da adubação nitrogenada e manejos de solo. Revista Brasileira de Milho e Sorgo, Sete Lagoas, v.9, n.32, p.135-146, 2010.

FERREIRA, M.G.; BRITO, M.E.; COSTA, F.B.D.; ARAÚJO FILHO, G.D.D.; ALVINO, F.C. Aspectos químicos e físicos dos grãos de milho doce sob estresse hídrico. Revista Brasileira de Agrotecnologia, Pombal, v.1, n.1, p.1-6, 2011.

FREIRE, F.M.; VIANA, M.C.M.; MASCARENHAS, M.H.T.; PEDROSA, M.W.; COELHO, A.M.; ANDRADE, C.L.T. Produtividade econômica e componentes da produção de espigas verdes de milho em função da adubação nitrogenada.

Revista Brasileira de Milho e Sorgo, Sete Lagoas, v.9, n.3, p.213-222, 2010. 

GARCIA, G.A.; GUERRA, L.C.;
HOOGENBOOM, G. Water use and water use efficiency of sweet corn under different weather conditions and soil moisture regimes. Agricultural Water Management, Amsterdam, v.96, n.10, p.1369-1376, 2009.

HEINEMANN, A.B.; SOUSA, S.A.V.; FRIZZONE, J.A. Determinação da lâmina ótima de água para cultura do milho doce na região de Sete Lagoas, MG. Revista Brasileira de Engenharia Agrícola e Ambiental, Campina Grande, v.5, n.1, p.147-151, 2001.

KHAZAEI, F.; AGHAALIKHANI, M. Nitrogen rate and plant density effect on dry matter accumulation and fresh ear yield of sweet corn. Agronomy Journal (Pajouhesh \& Sazandegi), Tehran, v.24, n.3, p.1-8, 2011.

KWIATKOWSKI, A; CLEMENTE, E. Características do milho doce (Zea mays L.) para industrialização. Revista Brasileira de Tecnologia Agroindustrial, Ponta Grossa, v.1, n.2, p.93-103, 2007.

LUCHSINGER, A.; CAMILO, F. Rendimiento de maíz dulce y contenido de sólidos solubles. Idesia, Arica, v.26, n.3, p.21-29. 2008.

LUZ, J.M.Q.; CAMILO, J.S.; BARBIERI, V.H.B.; RANGEL, R.M.; OLIVEIRA, R.C. Produtividade de genótipos de milho doce e milho verde em função de intervalos de colheita. Horticultura Brasileira, Brasília, v.32, n.2, p.163-167, 2014.

OKUMURA, R.S.; MARIANO, D.C.; ZACCHEO, P.V.C. Uso de fertilizante nitrogenado na cultura do milho: uma revisão. Pesquisa Aplicada \&
Agrotecnologia, Pombal, v.4, n.2, p.26-244, 2011.

OKUMURA, R.S.; MARIANO,D.D.C.; FRANCO, A.A.N.; ZACCHEO, P.V.C.; ZORZENONI, T.O. Sweet corn: Genetic aspects, agronomic and nutritional traits. Revista Brasileira de Tecnologia Aplicada nas Ciências Agrárias, Guarapuava, v.6, n.1, p.105-114, 2013.

PEREIRA FILHO, I.A.; CRUZ, J.C. Cultivares de Milho para o Consumo Verde. Sete Lagoas, Embrapa Milho e Sorgo, 2002. 7p. (Circular Técnica n.15).

SAWAZAKI, E.; ISHIMURA, I.; ROSSETO, C.J.; MAEDA, J.A.; SAES, L.A. Milho verde: avaliação da resistência à lagarta da espiga, da espessura do pericarpo e outras características agronômicas. Bragantia, Campinas, v.49, n.2, p.241-251, 1990.

SILVA, S.M.; OLIVEIRA, L.J.; FARIA. F.P.; REIS, E.F.; CARNEIRO, M.A.C. Atividade da enzima nitrato redutase em milho cultivado sob diferentes níveis de adubação nitrogenada e potássica. Ciência Rural, Santa Maria, v.41, n.11, p.1931-1937, 2011.

SOUSA, D.M.G.; LOBATO, E. Cerrado: Correção do solo e adubação. 2.ed. Brasília: Embrapa Informação Tecnológica, 2004. 416p.

SOUZA, E.; SORATTO, R. Efeito de fontes e doses de nitrogênio em cobertura, no milho safrinha, em plantio direto. Revista Brasileira de Milho e Sorgo, Sete Lagoas, v.5, n.3, p.395-405, 2006.

Syngenta $\quad$ Seeds. $<$ http://www.syngenta.com/ country/br/pt/produtosemarcas/sementes/Pages/ milho-doce-hibrido-tropical-plus.aspx $>$. Acesso em: Junho de 2015. 